Título da Exposição: Nazaré do Mocajuba

Autor(es): Alexandre Sequeira

Agência Financiadora: O autor

Cidade e Data de Pesquisa: Nazaré do Mocajuba, Curuçá, PA, 2004 a 2005.

Local da Exposição: Itinerante

Ficha Técnica: 10 tecidos/objetos pessoais com imagens fotográficas impressas e 10 fotografias em cor, com molduras brancas no tamanho de 50 x $40 \mathrm{~cm}$

Câmera: Nikon D90

\title{
NAZARÉ DO MOCAJUBA
}

Ananda Andrade do Nascimento Santos ${ }^{1}$

Meu primeiro contato com o trabalho de Alexandre Sequeira foi através da palestra $A$ Revitalização do caráter documental na fotografia contemporânea do Prof. Dr. Ronaldo Entler (Faculdade de Artes Plásticas da Fundação Armando Alvares Penteado) no II Ciclo de Diálogos em Antropologia e Imagem, Fortaleza-CE, em 2010. Entler trouxe trabalhos de Sequeira como $\mathrm{Meu}$ mundo Teu (uma série de quinze trabalhos que mesclam as trocas de cartas, fotografias e impressões sobre suas realidades estabelecidas por dois adolescentes que nunca se viram, mediadas por Sequeira na condução de encontros fotográficos individuais com cada um deles) e Nazaré do Mocajuba, o qual explorarei nessa resenha.

Alexandre Sequeira é artista plástico e fotógrafo, mestre em Arte e Tecnologia pela Universidade Federal de Minas Gerais e professor do Instituto de Ciências da Arte da Universidade Federal do Pará A constante nos trabalhos realizados por Sequeira, que muito interessa às discussões travadas por antropólogos visuais, é a ideia da alteridade/encontro com o outro e das práticas de restituição de imagens.

Nazaré do Mocajuba é uma pequena vila de pescadores localizada no município de Curuçá, nordeste do Pará. Sequeira narra, em sua dissertação intitulada Entre Lapinha da Serra e o Mata Capim: fotografia e relações de trocas simbólicas, que foi com o objetivo de fotografar a paisagem não-humana que chegou à vila, mas, nas palavras do autor, “o contato com os moradores e o pedido para que os fotografassem resultou num estreitamento de relações na medida em que sou acolhido e

1 Universidade Federal do Rio Grande do Sul, Brasil. 
reconhecido por todos como o retratista do lugar." (Sequeira, 2010:75) Como já é sabido e experenciado, o movimento da vida e do cotidiano constantemente nos aponta caminhos diversos a partir do encontro e da interação com o outro. No caso de Nazaré do Mocajuba, entre outros trabalhos do autor, a fotografia é utilizada como meio de interação e trocas simbólicas.

Sequeira, ao longo de dois anos (2004 a 2005) prestou serviços como fotografias para documentos, fotografias familiares e restauro de fotografias de antigas, além de participar ativamente de atividades da vila, como sair para pescar, plantar e conversar à beira da fogueira, o que permitiu uma convivência, um estreitamento de relações, uma afetação e um novo caminho para sua pesquisa: o fotógrafo foi convidado a entrar nas casas dos moradores e, a partir dessa intimidade, solicitou a cada um de seus fotografados um objeto afetivo cotidiano, alguns desgastados pelo tempo, de sua propriedade: cortina, toalha de mesa, lençol florido, rede, véu mosquiteiro etc. O resultado sensível são dez peças constituídas pelo objeto afetivo como suporte com a imagem em tamanho real do dono do objeto impressa neste a partir da técnica da serigrafia. Nesse processo, é importante destacar que muitos desses moradores da vila jamais haviam se visto em uma imagem fotográfica o que, segundo o autor, associado à contemplação dos objetos por parte de seus donos, acrescidos de suas imagens fotográficas em tamanho real, converteu-se em possibilidade de novas articulações que se colocavam para além da imagem. (Sequeira, 2010)

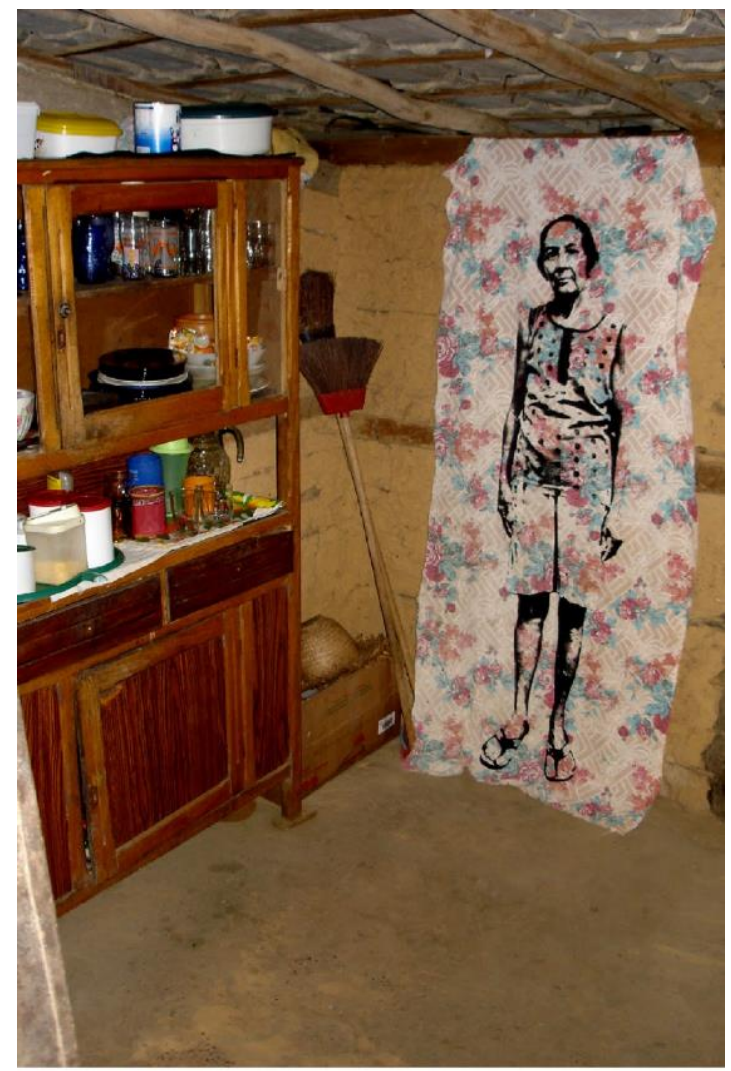

Foto 1 - Dona Alice, 2005. Autor: Alexandre Sequeira. 
Os moradores de Nazaré do Mocajuba fazem parte, desde o ano de 2004, do grupo de pessoas com as quais convivo, mesmo que esporadicamente. Dentre idas e vindas ao vilarejo, temos encontros que se realizam regularmente ao longo dos últimos seis anos sempre no mês de dezembro. Neles, nos reunimos às margens do rio Mocajuba para juntos celebrarmos o fim de mais um ano e reafirmarmos nossos laços de amizade e companheirismo. (Sequeira, 2010: 78)

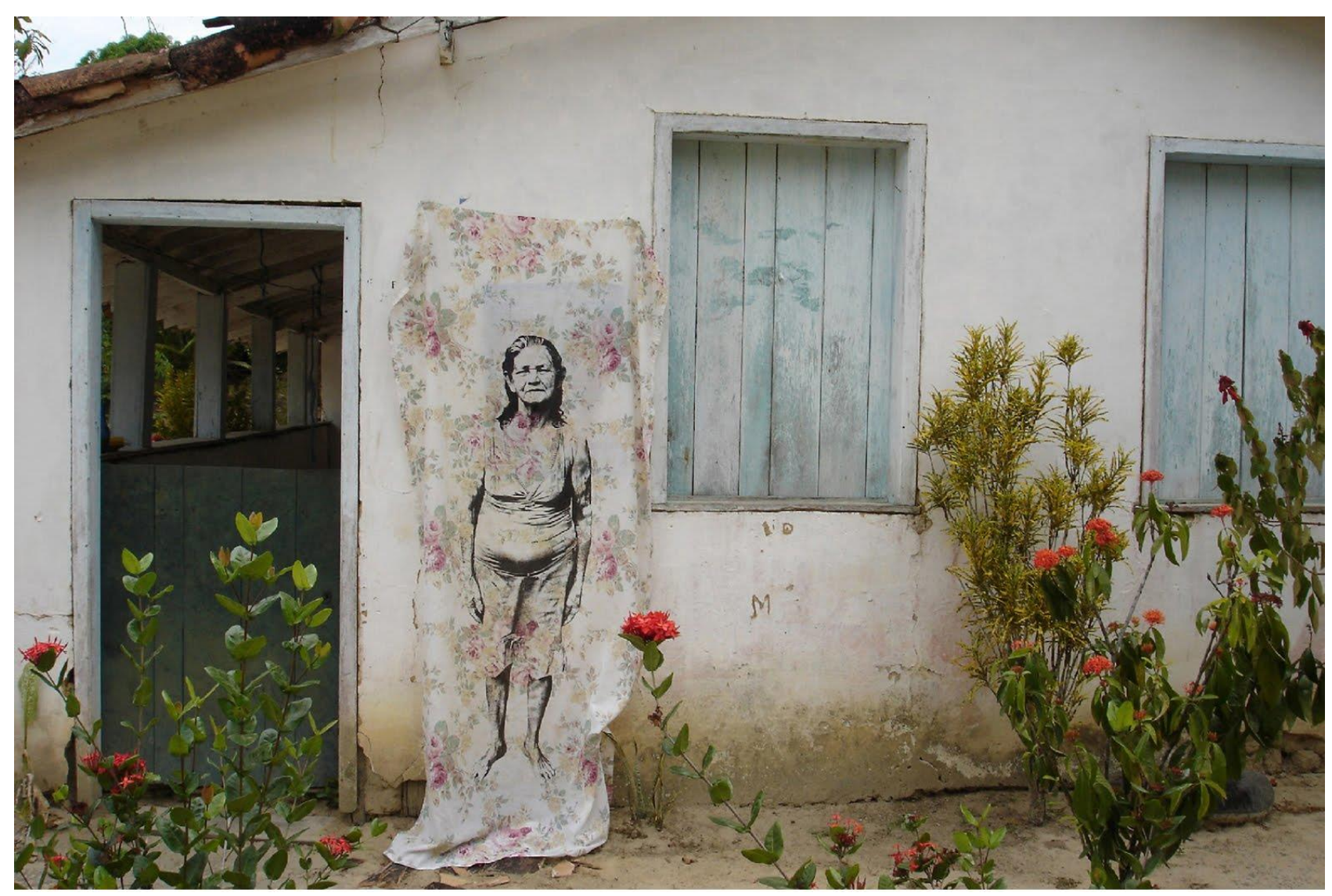

Foto 2 - Branca, 2005. Autor: Alexandre Sequeira. 


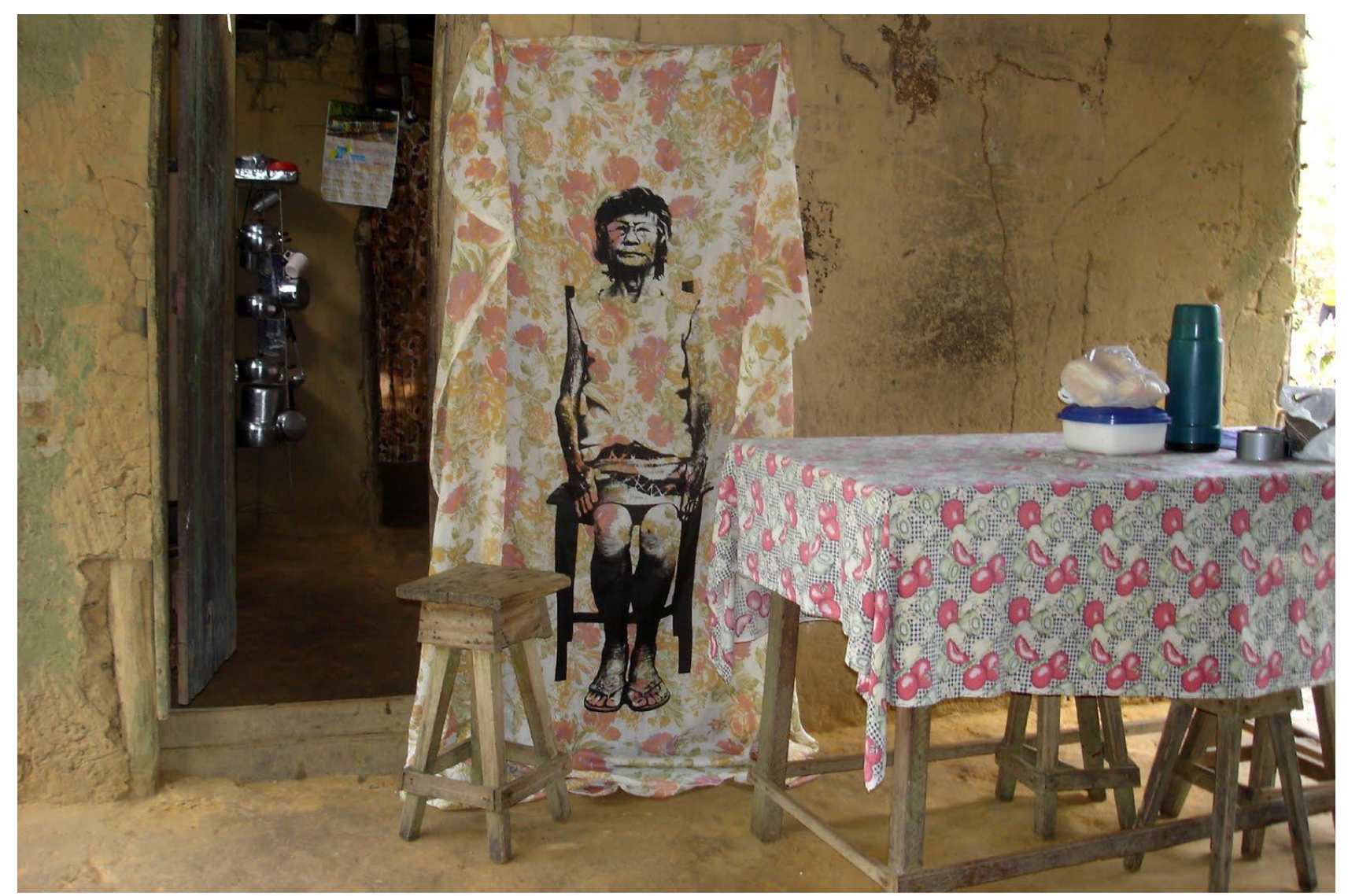

Foto 3 - Dona Francisca. Autor: Alexandre Sequeira.
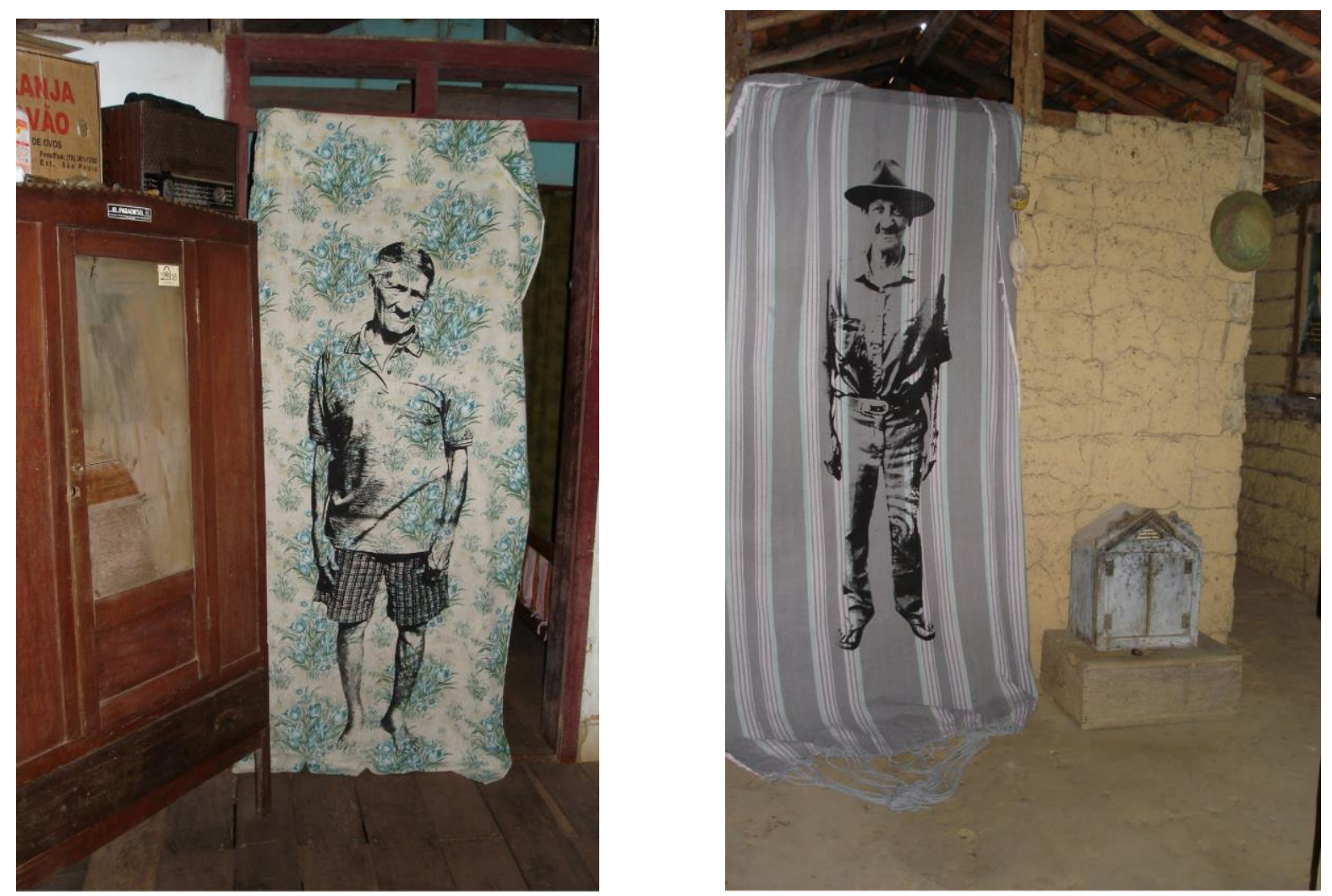

Foto 4 - Seu Suzano, 2005. Autor: Alexandre Sequeira. Foto 5 - Seu Carmelino, 2005. Autor: Alexandre Sequeira. 


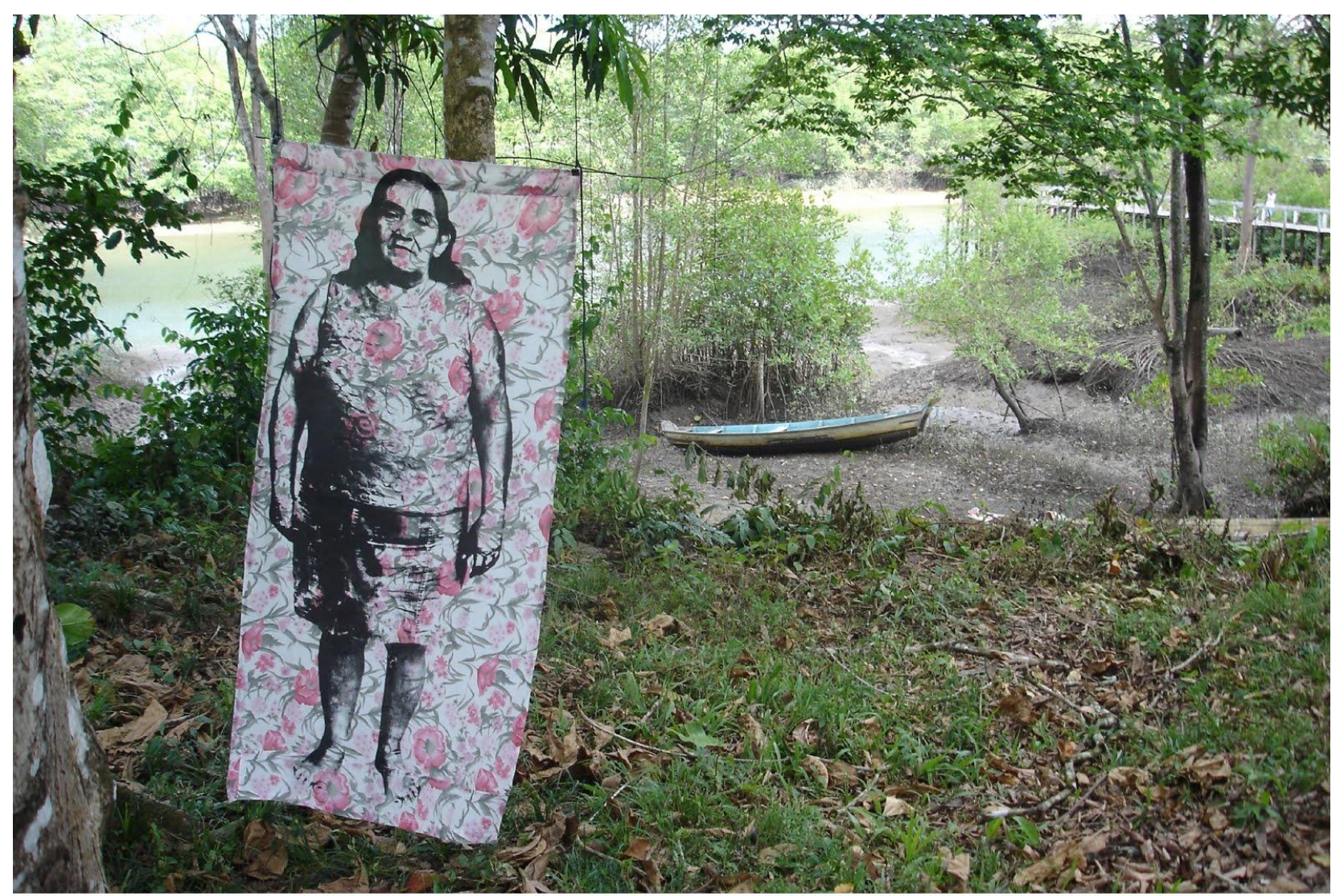

Foto 6 - Dona Benedita, 2005. Autor: Alexandre Sequeira.

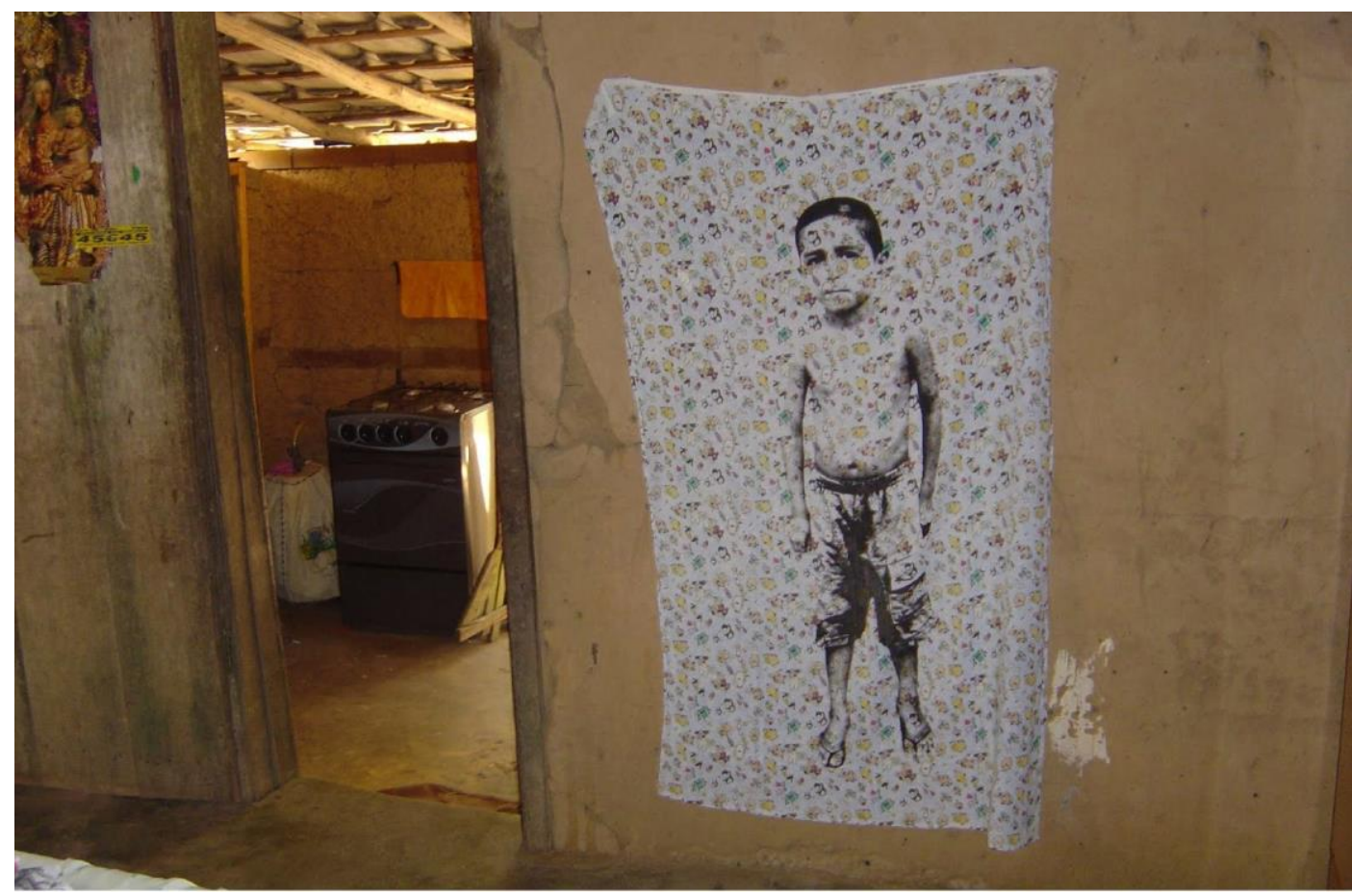

Foto 7 - Lucas, 2005. Autor: Alexandre Sequeira. 


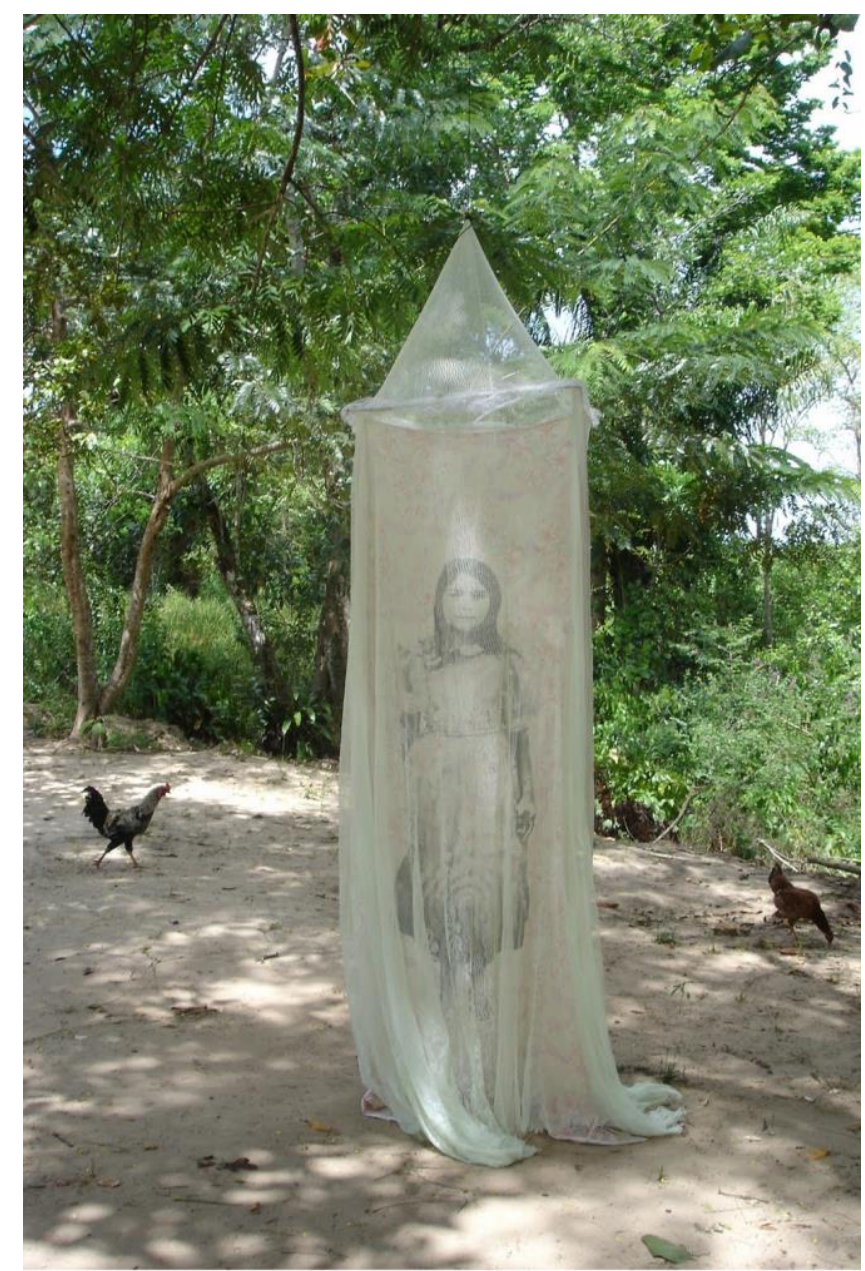

Foto 8 - Adriane, 2005. Autor: Alexandre Sequeira.

O segundo encontro com a obra de Sequeira e com o próprio fotógrafo veio em novembro de 2012, quando o artista participou da exposição coletiva Ecos Híbridos (26 de outubro a 9 de dezembro de 2012) no Museu de Arte Contemporânea do Ceará (MAC-CE), promovida pelo Fórum de Fotografia e com curadoria de Georgia Quintas. Na ocasião, eu atuava como arte-educadora no MAC-CE e tinha como função mediar o encontro das obras com os visitantes do museu, na continuação de uma rede de interações/afetos que se inicia na pequena Nazaré do Mocajuba, entre Sequeira e os moradores, e reverbera por onde passa. 


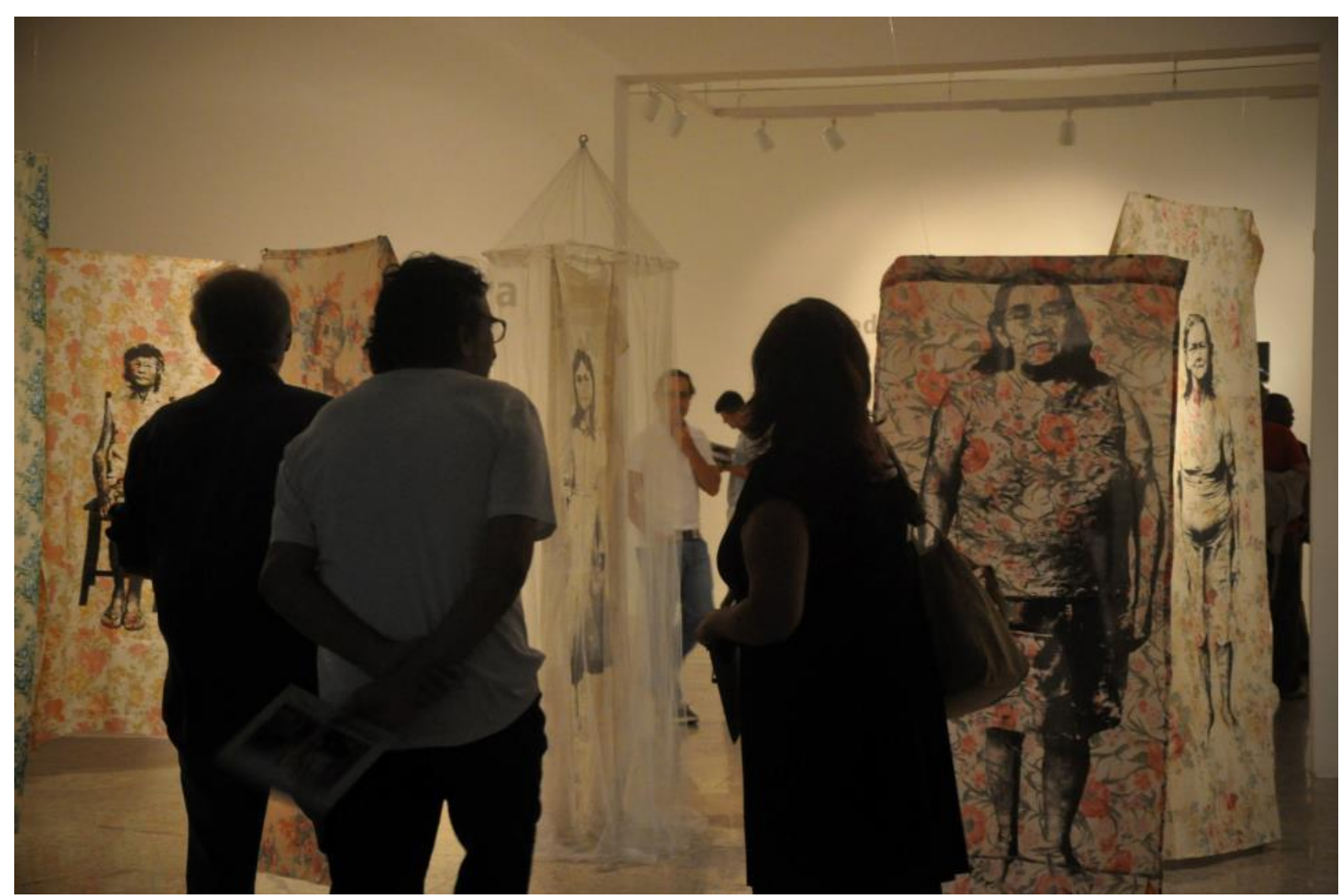

Foto 9 - Mediação e interação do público com as obras e com os educadores na abertura da exposição Ecos Híbridos. Autor: Marina Cavalcante

Foi na conversa da equipe de Ação Educativa do MAC com Sequeira que soube um pouco mais sobre a poética da exposição. O fotógrafo dá ênfase não apenas à dimensão do objeto como suporte da imagem fotográfica, mas também ao contexto afetivo das pessoas; para além dos objetos, também é de suma importância na exposição a presença das dez fotografias dos objetos restituídos nas casas/cotidianos dos fotografados.

As lentes de Sequeira nos revelam não só Dona Branca e Dona Francisca em seus tecidos floridos ou Seu Carmelino em sua rede ou Adriane em seu véu mosqueteiro, mas também a casa onde vivem, as flores do seu jardim, a varanda ao fundo onde se arma a rede para o "sono da tarde", o paneleiro, as paredes da casa de barro, o vestido da primeira comunhão, o chapéu repousado na parede, instrumentos de trabalho, o pequeno santuário de oração, e o pão com café que deve ter sido servido a Sequeira. As imagens fotográficas, nesse caso, não apenas são boas para pensar, mas também nos informam de interações travadas e de um jeito de ser e de estar no mundo. É perceptível o que Sequeira chama de um "entendimento da dimensão mais alargada da experiência fotográfica." 
O longo tempo de realização do projeto promove uma diluição dos papéis ocupados pelo propositor e participante, fazendo com que o fato artístico não resida mais na coisa - nesse caso, a fotografia em si -, nem no psiquismo do criador ou do participante, tomado isoladamente, mas ganhe sua verdadeira dimensão e sentido a partir das relações de afeto, confiança e respeito mútuo que se estabelecem entre as partes envolvidas. (Sequeira, 2010: 75)

Nesse sentido, é importante perceber, nessas relações traçadas entre Sequeira e os moradores de Nazaré do Mocajuba, a dimensão da ativa participação dos fotografados na circulação dessas imagens. O resultado foi exibido, primeiramente, apenas para os moradores da vila, às margens do Rio Mocajuba, onde eles se viram impressos em seus objetos pessoais numa exposição montada em forma de varão, com o vento e sonoridade natural da vila. Isso demonstra a responsabilidade e o compromisso ético na restituição aos fotografados e participantes do processo de pesquisa de Sequeira.

Na exposição montada na Casa das Onze Janelas, em dezembro de 2004, em Belém, os moradores, muitos destes nunca haviam saído da vila, visitaram e acompanharam a recepção do público das imagens fotográficas/objetos afetivos e também de imagens sonoras, que consistiam em 36 horas de sonoridades ambientes captados por Sequeira. O canto das aves e o barulho do Rio Mocajuba traziam para mais perto do público o cotidiano dos moradores que ali estavam representados e presentes.

A exposição, que é itinerante, já passou por vários países, entre eles, França, Inglaterra, Bélgica, China, Canadá, Estados Unidos, Uruguai. No Brasil já passou, além de Belém, por Manaus, Recife, São Paulo, Vitória, Belo Horizonte, Brasília, Rio de Janeiro, Brasília, Porto Alegre e Fortaleza. É por esse motivo que Sequeira considera o trabalho realizado em Nazaré do Mocajuba como "em processo", uma vez "a circulação das peças de tecido por diversas cidades se reverte em informação para os moradores da vila sobre esses diferentes contextos culturais onde eles são vistos." (Sequeira, 2010: 76). Além disso, valores obtidos a partir da exposição são encaminhados para os moradores da vila para que decidam, coletivamente, o que fazer com a renda. Essa dinâmica não serviria como um "pagamento" pela participação no processo. Nas palavras do autor:

\footnotetext{
Tal mecanismo, longe de servir como forma de ressarcimento por sua participação, se constitui parte integrante da experiência artística na medida em que promove uma maior compreensão por parte dos mesmos - em sua grande maioria, desconhecedores das regras ou valores que regem o universo das artes -, do papel dessas práticas no campo das relações de trabalho e geração de renda. (Sequeira, 2010: 76)
}

Sequeira, além de inspirar e afetar com sua poética e sensibilidade de comunicar processos de 
interação e alteridade social na experiência fotográfica, também coloca em foco uma extensa e necessária discussão sobre a responsabilidade e compromisso ético na pesquisa com imagens fotográficas. $\mathrm{Na}$ antropologia, temos o desafio/compromisso com um projeto científico de apresentar o discurso do Outro de uma maneira horizontal, um projeto bem próximo ao que Sequeira apresenta como caráter democrático em seu fazer artístico, buscando transpor os interlocutores da condição de testemunha para a condição de coprodutor, o que apontaria, segundo o autor, espaços-tempos regidos por outra ordem, uma dinâmica anti-hegemônica. Alcançar essa outra ordem é o que Sequeira vem tentando realizar em seus trabalhos, o que acredito que muito se assemelha às minhas pretensões e de vários outros colegas na antropologia. É isso que aprendi com a obra do Siqueira, que vem me afetando desde 2010.

Eu nunca conheci Dona Branca, mas nunca esquecerei de sua imagem florida, ou de Adriane em seu mosqueteiro, trajando o vestido da primeira comunhão. A pequena vila tem memória. Coletiva, individual e, agora, fotográfica; que vem se espalhando por todos os continentes. E são muitos que, assim como eu e Alexandre Sequeira, jamais esquecerão do Lucas, do Seu Suzano, da Dona Benedita e tantos outros moradores ilustres de Nazaré do Mocajuba.

\section{Referências}

SEQUEIRA, Alexandre. Entre Lapinha Serra e o Mata Capim. Dissertação de Mestrado em Artes da Escola de Belas Artes da Universidade Federal de Minas Gerais, 2010.

Recebido em: 20/09/2014

Aprovado em: 10/11/2014 